\title{
Pembuatan Dashboard Data Penginderaan Jauh Berbasis Web Menggunakan Platform GeoNode (Studi Kasus : Provinsi Jawa Timur)
}

\author{
Ari Matiur dan Lalu Muhamad Jaelani \\ Departemen Teknik Geomatika, Fakultas Teknik Sipil Lingkungan dan Kebumian, \\ Institut Teknologi Sepuluh Nopember (ITS) \\ e-mail:1mjaelani@geodesy.its.ac.id
}

\begin{abstract}
Abstrak-Penginderaan jauh memegang peran penting untuk mendukung berbagai sektor pembangunan dan pelestarian lingkungan. Pada pelaksanaannya penginderaan jauh tidak lepas dari penggunaan citra satelit untuk mendapatkan informasi di permukaan bumi. Citra satelit yang umum digunakan salah satunya adalah Landsat 8. Pada pendistribusiannya, citra ini bisa didapatkan dengan mengunduh melalui web earth explorer. Data yang didapat berupa data mentah yang mana tiap piksel citra merupakan nilai digital number. Data ini masih perlu dilakukan beberapa proses terlebih dahulu untuk dapat digunakan. Selain itu data citra satelit merupakan data raster yang memiliki ukuran penyimpanan data (storage) yang besar. Terlebih lagi untuk melakukan pengolahan data citra satelit dengan cepat membutuhkan spesifikasi komputer yang tinggi. Penelitian ini bertujuan untuk melakukan koreksi radiometrik (radiometric correction) pada citra Landsat 8 , setelah itu membuat sebuah dashboard data penginderaan jauh dimana data yang disediakan berupa citra bernilai reflektan permukaan (surface reflectance) yang sudah dikoreksi radiometrik, sehingga data yang diunduh dari dashboard siap digunakan. Metode koreksi radiometrik yang digunakan adalah Apparent Reflectance ArcGIS, sedangkan pembuatan dashboard menggunakan platform GeoNode. Hasil penelitian ini berupa website yang mampu menampilkan dan mengunduh citra yang sudah dikoreksi radiometrik. Website tersebut baru bisa diakses melalui komputer host dengan membuka alamat IP komputer virtual melalui browser. Raster yang bisa ditampilkan GeoNode adalah raster integer, sehingga citra reflektan permukaan yang berupa raster float harus diubah terlebih dahulu menjadi raster integer. Untuk mengubah citra reflektan permukaan menjadi raster integer digunakan faktor skala 10000.
\end{abstract}

Kata Kunci-Dashboard, GeoNode, Koreksi Radiometrik, Landsat 8, Penginderaan Jauh.

\section{PENDAHULUAN}

$\mathrm{P}$ ENGINDERAAN jauh telah lama memegang peran penting dan efektif dalam pemantauan tutupan lahan dengan kemampuannya menyediakan informasi mengenai keragaman spasial di permukaan bumi dengan cepat, luas, tepat, serta mudah [1]. Aktivitas penginderaan jauh sudah lama dilaksanakan di Indonesia sejak 1993 untuk mendukung berbagai sektor pembangunan dan pelestarian lingkungan [2]. Terlebih saat ini, beberapa citra satelit penginderaan jauh bisa diperoleh dengan mudah dan gratis, seperti citra satelit Landsat 8. Pada pendistribusiannya, citra satelit Landsat 8 bisa didapatkan dalam bentuk data mentah (raw data) ataupun data yang sudah diproses terlebih dahulu (processed data) sebelum dibagikan. Data-data tersebut paling umum bisa diunduh melalui web earth explorer milik USGS (https://earthexplorer.usgs.gov/).
Data penginderaan jauh sebelum bisa digunakan untuk berbagai tujuan perlu dilakukan beberapa proses terlebih dahulu diantaranya adalah proses koreksi geometrik dan radiometrik. Koreksi geometrik adalah transformasi citra hasil penginderaan jauh sehingga citra tersebut mempunyai sifat-sifat peta dalam bentuk, skala dan proyeksi [3] Sedangkan koreksi radiometrik adalah proses untuk merubah data dari format DN (Digital Number) ke radian atau reflektan. Terdapat dua jenis produk luaran citra berformat reflektan yang dihasilkan, yaitu Top of Atmosphere (TOA) atau reflektan yang tertangkap sensor dan Bottom of Atmosphere (BOA) atau reflektan pada objek yang telah terkoreksi atmosfer. Proses koreksi radiometrik dibagi menjadi dua yaitu kalibrasi radiometrik dan koreksi atmosfer. Kalibrasi radiometrik bertujuan merubah DN ke radian atau reflektan menggunakan parameter yang tersedia di metadata, sedangkan koreksi atmosfer bertujuan menurunkan reflektansi objek dari total radiansi TOA setelah proses normalisasi kondisi pencahayaan dan penghapusan efek atmosfer [4]. Pada citra Landsat 8, citra yang sudah terkoreksi geometrik dan radiometrik bisa didapatkan dengan memesan terlebih dahulu kemudian bisa diunduh dengan gratis. Meskipun data sudah terkoreksi radiometrik, untuk bisa diterapkan untuk berbagai keperluan data tersebut masih perlu diproses lagi. Proses pengolahan citra setelah keoreksi geometrik dan radiometrik akan berbeda-beda sesuai dengan kebutuhan. Selain itu data citra satelit merupakan data spasial format raster, dimana data ini memerlukan penyimpanan memori yang besar [5]. Oleh karena itu diperlukan sebuah dashboard yang mampu menyediakan data citra satelit yang sudah diproses terlebih dahulu sebelum diunduh.

Penelitian ini bertujuan untuk melakukan koreksi radiometrik (radiometric correction) pada citra Landsat 8 , dan juga membuat sebuah dashboard data penginderaan jauh dimana data yang disediakan berupa citra bernilai reflektan permukaan (surface reflectance) yang sudah dikoreksi radiometrik, sehingga data yang diunduh dari dashboard siap digunakan.

\section{METODOLOGI PENELITIAN}

\section{A. Lokasi Penelitian}

Lokasi penelitian ini adalah Provinsi Jawa Timur, terletak pada geografis $111^{\circ} 0^{\prime}$ sampai $114^{\circ} 04^{\prime}$ BT dan $7^{\circ} 12^{\prime}$ sampai $8^{\circ} 48^{\prime \prime}$ LS, Jawa Timur sendiri merupakan Provinsi terluas yang ada di Pulau Jawa dengan luas wilayah sebesar 47.963 $\mathrm{km}^{2}$ yang meliputi dua bagian utama yaitu daratan Jawa Timur dan Kepulauan Madura. Wilayah daratan Jawa Timur sebesar 88,70 persen atau $42.541 \mathrm{~km}^{2}$, sementara luas Kepulauan Madura memiliki luas 11.30 persen atau sebesar 


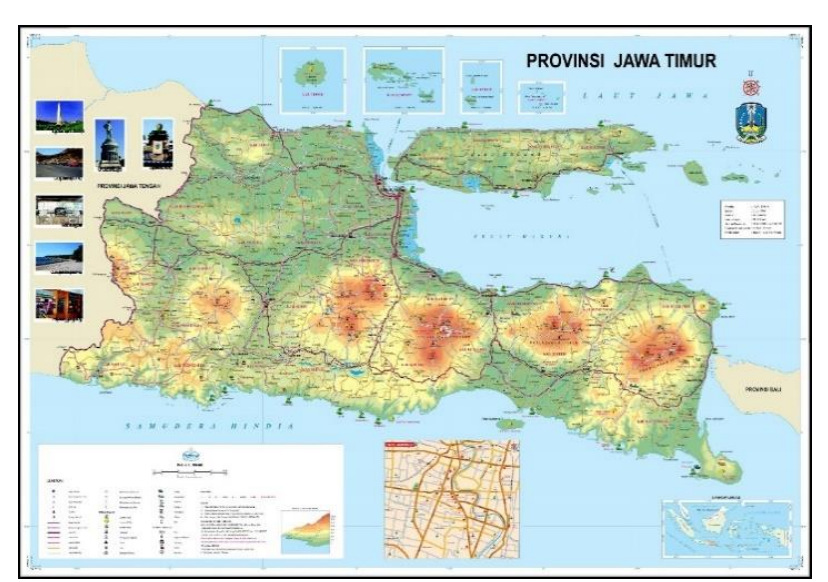

Gambar 1. Lokasi Penelitian Provinsi Jawa Timur. (BAKOSURTANAL, 2003)

$5.422 \mathrm{~km}^{2}$. Jumlah penduduknya pada tahun 2010 mencapai 37.476.757 jiwa (BPS 2010).

\section{B. Data dan Peralatan}

Adapun data dan peralatan yang digunakan dalam penelitian tugas akhir ini adalah sebagai berikut :

\section{1) Data}

Data yang digunakan dalam penelitian ini antara lain :

Data citra Landsat 8 level 1 wilayah Jawa Timur didapat dari situs earth explorer milik USGS (https://earthexplorer.usgs.gov). Berikut adalah product identifier citra yang digunakan.

Tabel 1.

Product Identifier Citra yang Digunakan

\begin{tabular}{cc} 
& Product Identifier Citra yang Digunakan \\
\hline \hline No. & Product Identifier \\
\hline 1 & LC08_L1TP_119065_20170815_20170825_01_T1 \\
3 & LC08_L1TP_119066_20170511_20170516_01_T1 \\
4 & LC08_L1TP_118065_20170909_20170927_01_T1 \\
5 & LC08_L1TP_118066_20170824_20170912_01_T1 \\
6 & LC08_L1TP_117065_20170918_20170929_01_T1 \\
7 & LC08_L1TP_117066_20170918_20170929_01_T1 \\
8 & LC08_L1TP_119065_20160828_20170321_01_T1 \\
9 & LC08_L1TP_118065_20160828_20170321_01_T1 \\
10 & LC08_L1TP_118066_20160906_20170321_01_T1 \\
11 & LC08_L1TP_117065_20161017_20170319_01_T1 \\
12 & LC08_L1TP_117066_20161017_20170319_01_T1 \\
13 & LC08_L1TP_119065_20151013_20170403_01_T1 \\
14 & LC08_L1TP_119066_20150911_20170404_01_T1 \\
15 & LC08_L1TP_118065_20151022_20170402_01_T1 \\
16 & LC08_L1TP_118066_20150904_20170404_01_T1 \\
17 & LC08_L1TP_117065_20150913_20170404_01_T1 \\
18 & LC08_L1TP_117066_20150913_20170404_01_T1 \\
19 & LC08_L1TP_119065_20140924_20170419_01_T1 \\
20 & LC08_L1TP_119066_20141010_20170418_01_T1 \\
21 & LC08_L1TP_118065_20140901_20170420_01_T1 \\
22 & LC08_L1TP_118066_20140901_20170420_01_T1 \\
23 & LC08_L1TP_117065_20140926_20170419_01_T1 \\
24 & LC08_L1TP_117066_20140926_20170419_01_T1 \\
\hline \hline
\end{tabular}

Shapefile batas administrasi kota/kabupaten Provinsi Jawa Timur skala 1:25000 didapat dari situs InaGeoportal BIG (http://tanahair.indonesia.go.id/portal).

\section{2) Peralatan}

Alat yang digunakan dalam penelitian ini meliputi perangkat keras berupa Komputer serta perangkat lunak ArcGIS 10.5.1, GeoNode 2.8, Oracle VM Virtual Box 5.2.12 dan WinSCP

\section{Tahap Pengolahan Data}

Tahap pengolahan data dari penelitian ini dijelaskan pada uraian berikut :

\section{1) Koreksi Radiometrik}

Koreksi radiometrik ditujukan untuk menghilangkan efek atmosfer pada citra. Dalam penelitian ini koreksi rediometrik menggunakan fungsi Apparent Reflectance ArcGIS. Fungsi ini menyesuaikan nilai digital number menjadi reflektan permukaan berdasarkan sudut akuisisi matahari, data akuisisi dan spesifikasi sensor satelit. Fungsi ini hanya bisa digunakan untuk beberapa sensor satelit seperti Landsat MSS, Landsat TM, Landsat ETM+, Landsat 8, IKONOS, QuickBird, GeoEye-1, RapidEye, DMCii, WorldView-1, WorldView-2, SPOT 6, dan Pleiades [6].

\section{2) Spectral Subset}

Spectral subset bertujuan untuk memisahkan kanal-kanal citra menjadi kanal yang digunakan saja, dalam penelitian ini kanal yang digunakan adalah kanal 2, 3, 4 dan 5.

3) Mosaik Citra

Mosaik citra bertujuan untuk menggabungkan citra yang terpisah menjadi satu file GeoTiff. Citra Landsat 8 yang digunakan untuk menutupi seluruh Provinsi Jawa Timur sebanyak 6 scene citra.

4) Mengubah Raster Float Menjadi Integer

Raster float diubah menjadi integer dengan cara mengkalikan faktor skala 10000, penggunaan faktor skala 10000 sesuai dengan faktor skala yang digunakan oleh USGS [7]. Setelah dikalikan faktor skala raster masih berupa float. Untuk mengubah menjadi integer menggunakan toolbox Int ArcGIS. Setelah data menjadi integer maka tiap piksel raster akan menjadi nilai integer yang tidak memiliki angka desimal.

\section{5) Instalasi Server}

Instalasi server adalah melakukan instalasi operating system (OS) yang akan menjadi server. Operating system yang digunakan untuk menjadi server pada penelitian ini adalah Ubuntu Server 16.04. Instalasi operating system dilakukan didalam komputer virtual (virtual machine), perangkat lunak virtual machine yang digunakan dalam penelitian ini adalah Oracle VM Virtual Box 5.2.12.

6) Instalasi GeoNode

Instalasi GeoNode dilakukan pada Ubuntu Server 16.04 dengan menjalankan beberapa perintah melalui terminal. Setelah GeoNode terinstal, alamat homepage GeoNode diatur menggunakan alamat IP komputer virtual [8].

\section{7) Pembuatan Super Account}

Pembuatan super akun bertujuan untuk membuat akun yang akan manjadi administrator dashboard. Akun ini dapat membuat akun lain, menghapus akun lain serta mengedit semua data yang ada pada dashboard. Pembuatan akun ini dilakukan dengan menjalankan perintah pada terminal.

8) Penyesuaian Antarmuka GeoNode

Penyesuaian tampilan GeoNode bertujuan untuk merubah tampilan default menjadi tampilan yang kita inginkan. Penyesuaian dilakukan dengan mengedit file css default yang ada setelah instalasi, file ini di-copy terlebih dahulu ke komputer host dengan menggunakan perangkat lunak WinSCP, setelah file ini diedit kemudian di-copy ke komputer virtual untuk menggantikan (replace) file default.

\section{9) Mengunggah Data ke Dalam Dashboard}

Data-data yang sudah diolah diunggah ke dalam dashboard yang sudah diubah tampilannya. Mengunggah data dilakukan langsung dari user interface GeoNode. Data ini diatur agar bisa diunduh oleh siapa saja tetapi bisa diedit oleh akun tertentu [9]. 


\section{0) Layouting dan Membuat Metadata}

Data shapefile yang diunggah akan memiliki tampilan layout default, untuk mengedit layout tersebut dapat dilakukan langsung pada dashboard dengan login menggunakan super akun atau akun yang mengunggah data tersebut atau juga akun tertentu yang diberikan hak akses. Untuk mengedit metadata juga memerlukan hak akses yang sama seperti mengedit layout.

\section{HASIL DAN ANALISA}

\section{A. Hasil Pengolahan Citra}

Hasil pengolahan citra berupa citra mosaik dari 6 scene citra landsat 8. Citra ini memiliki 4 kanal (red, green, blue, near infrared). Citra ini akan diunggah terpisah tiap kanalnya, sehingga akan ada 4 layer citra pada dashboard untuk tiap tahunnya.

Selain itu akan ada citra multispectral natural color yang diunggah pada dashboard. Citra ini berguna untuk analisa langsung pada dashboard.

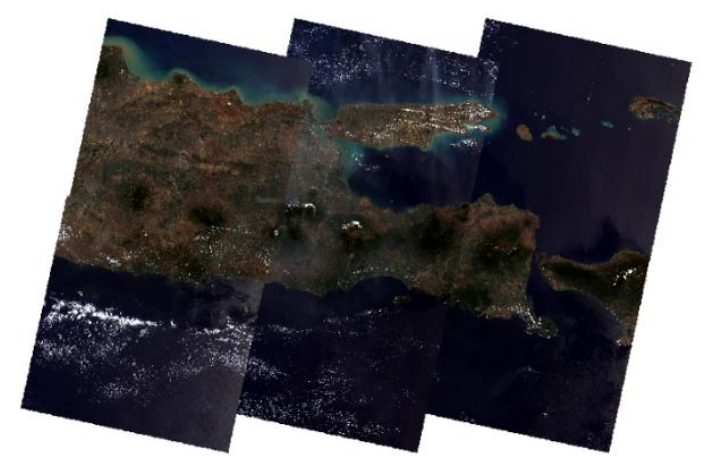

Gambar 2. Hasil Pengolahan Citra Tahun 2014.

\section{B. Hasil Instalasi dan Interface Dashboard}

Instalasi GeoNode dilakukan pada komputer virtual yang terinstal Ubuntu Server 16.04. Hasil instalasi GeoNode tidak bisa ditampilkan pada Ubuntu Server dikarenakan operating system ini tidak terinstal graphic user interface (GUI). Dashboard dapat ditampilkan melalui komputer host dengan mengakses IP GeoNode melalui browser, alamat IP ini sudah dikonfigurasi dari komputer virtual. Alamat IP yang digunakan menggunakan protokol DHCP, sehingga alamat IP dikonfigurasi secara manual. Alamat IP yang digunakan adalah 192.168.101.3

Sedangkan penyesuaian tampilan dashboard dilakukan dari komputer host dengan menyalin file dari komputer virtual lalu mengeditnya melalui komputer host, kemudian file dipindahkan kembali ke komputer virtual untuk menggantikan file default yang ada pada komputer virtual. Proses pertukaran file antara komputer virtual dan komputer host melalui perangkat lunak WinSCP.

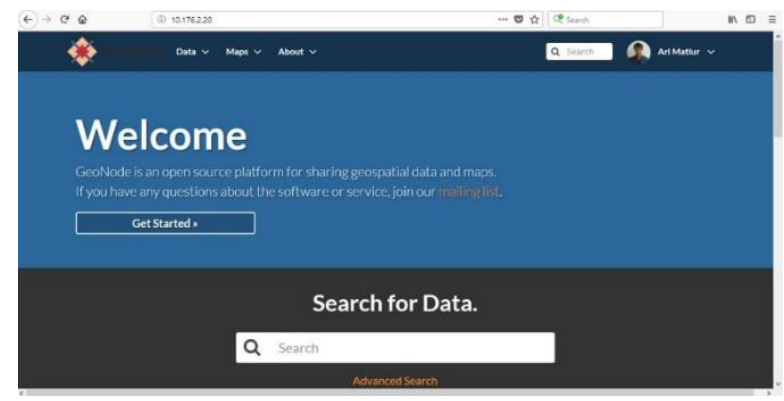

Gambar 3. Tampilan home GeoNode yang sudah diedit

\section{Layer Dashboard}

Layer yang sudah diunggah pada dashboard dapat ditampilkan dan dibuat layout-nya melalui browser. Berikut adalah layer Batas Administrasi Kabupaten Provinsi Jawa Timur.

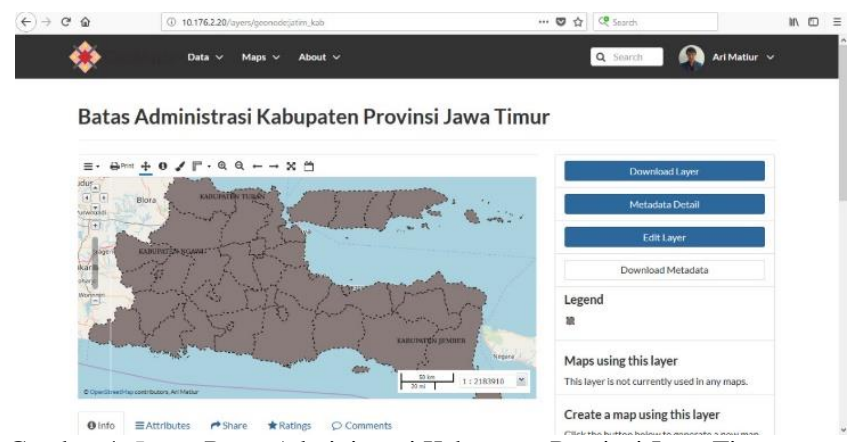

Gambar 4. Layer Batas Administrasi Kabupaten Provinsi Jawa Timur.

Layer format raster yang diunggah pada dashboard tidak bisa dibuat layout-nya. Layout yang ditampilkan berupa kombinasi pewarnaan RGB 8 bit untuk raster natural colour, sedangkan untuk raster NIR (near infrared) yang diunggah terpisah dari kanal lainnya ditampilkan dengan pewarnaan gray scale 8 bit.

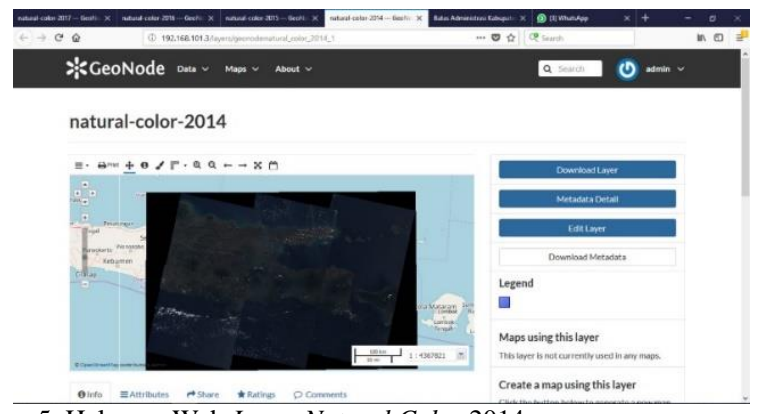

Gambar 5. Halaman Web Layer Natural Color 2014.

\section{Analisa}

Layer raster yang diunggah pada dashboard secara default akan muncul seperti biasa tanpa masalah jika berupa raster integer. Sedangkan untuk raster float perlu mengunggah file styled layer descriptor (SLD) yang dibuat untuk raster float sehingga raster bisa ditampilkan pada dashboard. Layer raster float yang diunggah tanpa mengunggah file SLD tidak bisa ditampilkan (blank), tetapi jika raster ini diunduh kemudian dibuka dengan perangkat lunak pengolahan citra, citra tersebut bisa ditampilkan tanpa ada masalah. Selain itu raster float memiliki ukuran file yang sangat besar sehingga sering gagal ketika mengunggahnya ke dashboard [10].

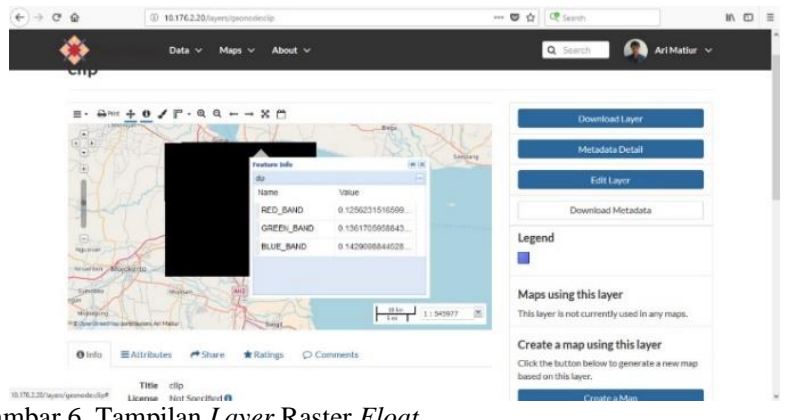

Gambar 6. Tampilan Layer Raster Float.

Citra yang sudah diolah tidak bisa diklasifikasi untuk mendapatkan informasi tutupan lahan dikarenakan citra yang 
sudah diolah merupakan citra mosaik yang memiliki nilai reflektan yang berbeda pada masing-masing scene citra untuk objek yang sama. Berikut adalah kesalahan hasil klasifikasi karena citra yang diklasifikasi sudah dimosaik.

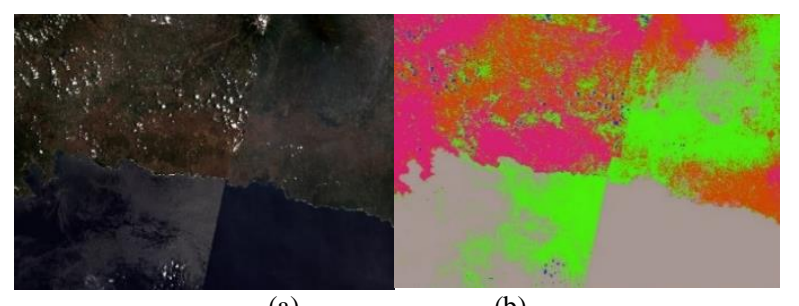

(a)

(b)

Gambar 7. (a) Citra sebelum diklasifikasi; (b) Raster hasil klasifikasi.

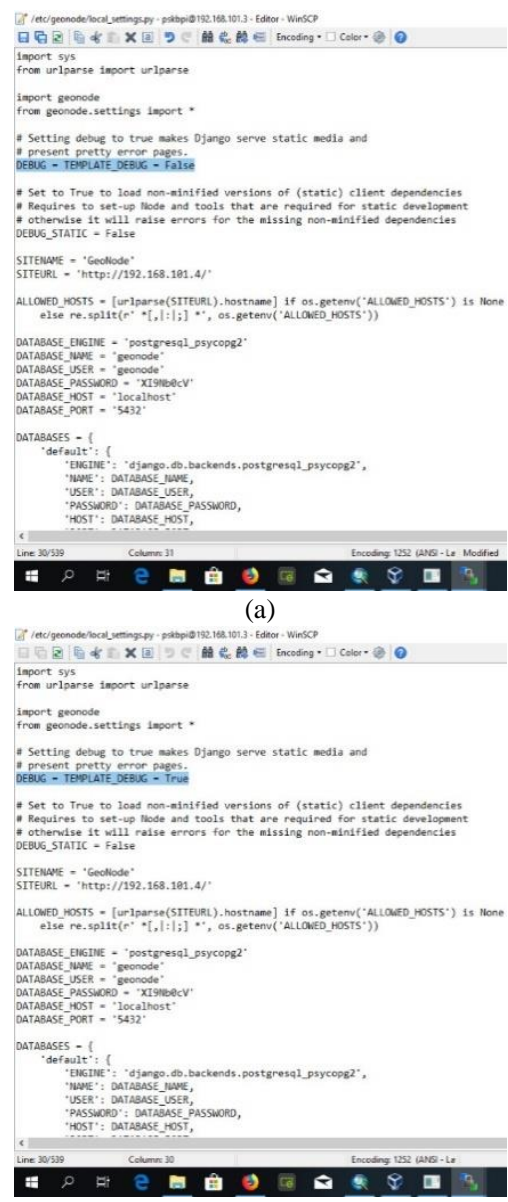

(b)

Gambar 8. (a) File "local setting.py" sebelum diubah; "local_setting.py" setelah diubah.

(b) File

Ketika pertama kali melakukan proses pengunggahan data ke dalam dashboard, proses tersebut tidak berhasil. Penyebab kegagalan data yang tidak terunggah dikarenakan terdapat code yang harus diubah pada file "local_settings.py", file tersebut berada pada lokasi "etc/geonode/local_settings.py". Code yang harus diubah adalah "DEBUG $=$ TEMPLATE_BUG $=$ False" menjadi "DEBUG $=$ TEMPLATE BUG ${ }^{-}=$True". Setelah code tersebut diubah, Apache server harus di-restart terlebih dahulu agar code baru yang sudah diubah digunakan oleh geonode. Untuk me-restart Apache server, login terlebih dahulu sebagai root kemudian jalankan perintah "service apache2 restart" pada ubuntu (Gambar 8).

\section{KESIMPULAN}

Raster yang diunggah ke dalam dashboard akan bisa langsung ditampilkan jika bertipe integer. Sedangkan raster tipe float perlu mengunggah file SLD untuk dapat menampilkan layer. Solusi yang digunakan pada permasalahan ini adalah dengan mengubah data reflektan permukaan Landsat 8 yang bertipe float menjadi integer. Untuk mengubah tipe raster digunakan faktor skala 10000.

Untuk saat ini dashboard hanya bisa diakses melalui komputer host saja, dikarenakan sistem jaringan yang digunakan pada penelitian ini memiliki satu server (komputer virtual) dan satu client (komputer host) saja. Agar dashboard bisa dikases secara publik, platform GeoNode harus terinstal pada komputer yang alamat IP-nya bisa diakses secara publik. Komputer yang dimaksud adalah komputer server yang ada pada DPTSI - ITS (Direktorat Pengembangan Teknologi dan Sistem Informasi - ITS) karena jaringan internet yang digunakan merupakan jaringan internet ITS.

Adapun saran untuk penelitian selanjutnya adalah perlu dilakukan kajian tentang pembuatan file SLD sehingga data yang diunggah merupakan data asli (float) sehingga data yang diunduh juga merupakan raster float.

\section{UCAPAN TERIMA KASIH}

Penulis A. M. mengucapkan terima kasih kepada Pusat Studi Kebumian, Bencana dan Perubahan Iklim ITS (PSKBPI-ITS) atas dukungan fasilitas dan bimbingan selama penelitian ini berlangsung.

\section{DAFTAR PUSTAKA}

[1] M. C. Hansen, R. S. DeFries, J. R. G. Townshend, dan R. Sohlberg, "Global Land Cover Classification at $1 \mathrm{~km}$ Spatial Resolution Using a Classification Tree Approach," Int. J. Remote Sens., vol. 21, no. 6, hal. 1331-1364, 2000

[2] D. Kushardono, R. Dewanti, K. A. Sambodo, dan R. Arief, "Kebutuhan Pengguna Data Penginderaan Jauh di Indonesia: Studi Awal Untuk Conceptual Design Review Satelit SAR Ekuatorial Indonesia INARSSAT-1," Int. Conf. Indones. Soc. Remote Sens., hal. 510-520, 2016.

[3] P. M. Mather, Computer Processing of Remotely Sensed Images. An Introduction. New York: John Willey and Sons, 1987.

[4] V. D. Sari, M. Taufik, dan L. M. Jaelani, "Perbandingan Pengaruh Koreksi Radiometrik Citra Landsat 8 Terhadap Indeks Vegetasi Pada Tanaman Padi," Pros. Semin. Nas. Apl. Teknol. Prasarana Wil., hal. 13-20, 2015.

[5] E. Prahasta, Sistem Informasi Geografis Konsep-Konsep Dasar (Perspektif Geodesi dan Geomatika). Bandung: Informatika, 2009. [6] ESRI, "Apparent Reflectance Function," 2017. [Daring]. Tersedia pada: http://desktop.arcgis.com/en/arcmap/10.5/managedata/raster-and-images/apparent-reflectance-function.htm. [Diakses: 04-Des-2018].

[7] USGS, "Provisional Landsat 8 Surface Reflectance Data Available," 2014. [Daring]. Tersedia pada: https://landsat.usgs.gov/provisional-landsat-8-surface-reflectancedata-available. [Diakses: 04-Des-2018].

[8] OSGeo, “Quick Installation Guide,” 2017. [Daring]. Tersedia pada:

http://docs.geonode.org/en/master/tutorials/install_and_admin/qui ck_install.html. [Diakses: 04-Des-2018].

[9] OSGeo, "Uploading a Layer," 2017. [Daring]. Tersedia pada: http://docs.geonode.org/en/master/tutorials/users/managing_layer s/upload.html. [Diakses: 04-Des-2018].

[10] GitHub, "My geotiff layer only show black scene \#3787," 2018 [Daring]. Tersedia pada: https://github.com/GeoNode/geonode/issues/3787\#issuecomment -386557824. [Diakses: 04-Des-2018]. 